\title{
PLASMINOGEN ACTIVATOR IN HUMAN TEARS
}

\author{
J. D. STEVENS, ${ }^{1}$ J. M. MARSHALL,${ }^{2}$ L. BENJAMIN, ${ }^{1}$ S. A. CEDERHOLM-WILLIAMS ${ }^{2}$, \\ A. J. BRON ${ }^{1}$ \\ Oxford
}

\begin{abstract}
SUMMARY
Measurements were made of the nature and levels of plasminogen activator in human tears using, as a model of inflammation, patients undergoing cataract surgery. Tissue plasminogen activator (t-PA) but not urokinase plasminogen activator (u-PA) was found in tears. A wide variation in the range of $\mathrm{t}-\mathrm{PA}$ in pre-operative tears was found. In those patients not receiving per-operative subconjunctival betamethasone a significant rise in t-PA was found in tears on the first post-operative day over preoperative levels. A significant fall was noted in those receiving per-operative subconjunctival betamethasone.
\end{abstract}

Plasmin is a potent protease involved in fibrinolysis and in situations of tissue remodelling and neoplasia. It is formed by the action of plasminogen activator (PA) on plasminogen (Plg), an abundant plasma protein. ${ }^{1}$ There are two major endogenous PAs: tissue plasminogen activator (t-PA) of relative molecular mass about $68000\left(M_{\mathrm{r}} 68 \mathrm{k}\right)$, and urokinase (u-PA) of $M_{\mathrm{r}} 54 \mathrm{k}$ and $34 \mathrm{k}$ in its higher and lower molecular weight forms (HMW and LMW) respectively.

\section{PA-Plasmin System}

Tissue plasminogen activator (t-PA) is essential to vascular fibrinolysis. It binds to fibrin which stimulates its plasminogen activating activity and it is produced and released by vascular endothelial cells. ${ }^{2}$ Urokinase (UK or u-PA) does not bind to fibrin and is concerned with tissue remodelling and cell migration. It is synthesised as a single chain inactive proenzyme, pro-urokinase (pro-UK), by a variety of cells including epithelial, ${ }^{3}$ fibroblastic and inflammatory cells. Many cells bind pro-UK and HMW-UK without loss of PA activity and with relative protection from the action of PA inhibitors. Although binding of u-PA to fibrin does not occur, fibrin will stimulate $\mathrm{u}-\mathrm{PA}$ induced thrombolysis.

\section{PA-Plasmin Inhibitors}

The action of plasmin is controlled by naturally occurring

From: ${ }^{1}$ Department of Ophthalmology, University of Oxford and Oxford Eye Hospital, Oxford, UK; ${ }^{2}$ Nuffield Department of Obstetrics and Gynaecology, John Radcliffe Hospital, Oxford, UK.

Correspondence to: Mr. J. D. Stevens, Moorfields Eye Hospital, City Road, London EC1V 2PD, UK. inhibitors; these include $\alpha 2$-antiplasmin a specific plasmin inhibitor, $\alpha 2$-macroglobulin, a non-specific inhibitor of plasmin, and a series of specific inhibitors of plasminogen activators such as plasminogen activator inhibitor-1 and -2 (PAI-I and PAI-2) and protease nexin, a cell surface inhibitor, which have differing affinities for t-PA and u-PA (e.g. PAI-1 is a more potent inhibitor of t-PA than $\mathrm{u}$-PA whereas PAI-2 is more effective against $\mathrm{u}-\mathrm{PA}$ ). PAI-1 and PAI-2 have little effect on plasmin activity. ${ }^{1}$

\section{Tissue Distribution}

Immunoreactive t-PA is widely distributed in ocular tissues, including the corneal endothelium and epithelium, the conjunctiva, the trabecular meshwork, lens epithelium, peripheral vitreous, inner retina, and all vascular endothelia. ${ }^{4}$ The concentration in human aqueous humour is low, ${ }^{5,6}$ while it is present both in the tears and in the lacrimal fluid.

Roles proposed for ocular PA have included remodelling (lens epithelium), regulation of the resistance to aqueous outflow (trabecular meshwork) and maintenance of canalicular patency (tears). The potential therapeutic value of fibrinolytic agents has been explored in the treatment of hyphaema, vitreous haemorrhage and retinal vascular occlusion.

Berman et $a{ }^{7}{ }^{7}$ proposed that PA may play an important part in retarded epithelial resurfacing and stromal melting after alkali burns. Resurfacing of the cornea after a corneal abrasion is associated with the appearance of fibrin and fibronectin (FN) at the stromal surface. The cell-binding domain of the FN offers an essential scaffold to the ingrowing epithelium, which affords attachment to the underlying basal lamina. Blocking epithelial binding sites with synthetic FN cell-binding domain fragments ${ }^{8}$ blocks pigment epithelial binding sites. ${ }^{9}$ Berman has proposed that some indolent healing may be due to excessive tear plasmin activity, acting both by digesting FN and by releasing FN fragments to block epithelial FN binding sites. This concept is given further support by Salonen $e t$ al. ${ }^{10}$ and Hayashi et al. ${ }^{11}$ who have demonstrated increased tear plasmin activity in a variety of corneal disorders including indolent corneal ulceration. 
$\begin{array}{llllllllllll}1 & 2 & 3 & 4 & 5 & 6 & 7 & 8 & 9 & 10 & 11 & 12\end{array}$

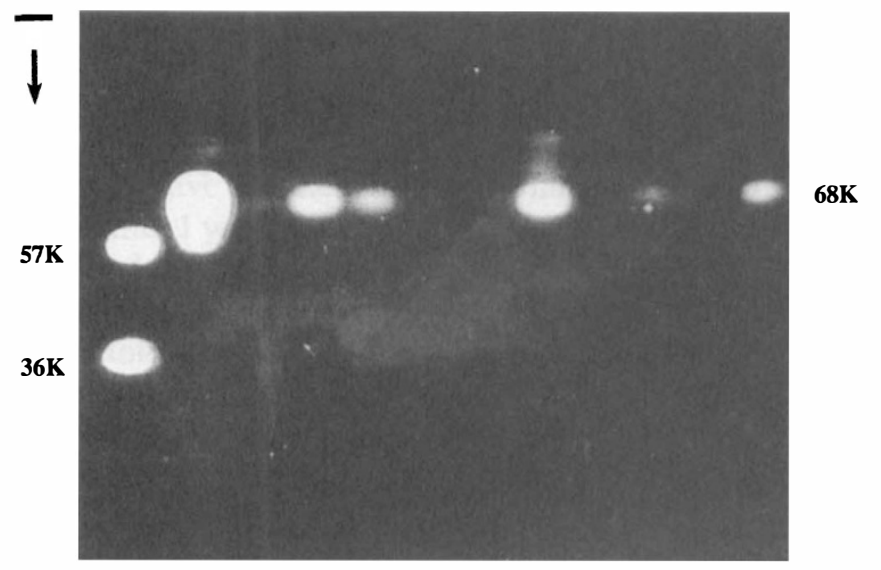

Fig. 1. Zymography film showing $u-P A$ and $t-P A$ standards run alongside a mixture of tear samples. Arrow shows direction of movement during electrophoresis. Horizontal bar above arrow is the starting line for the samples. Lane 1,u-PA standard with low molecular weight species (36k) nearest the bottom of the figure and the highest (57k) nearest the top of the figure. Lane 2, $t$-PA standard (68k). Lanes 3-12, tear samples: 3, 5, 11 and 12, pre-operative; 4, day 1 post-operative; 6 and 10, day 2 postoperative.

Berman et al. ${ }^{7}$ and Wang et al. ${ }^{12}$ have demonstrated that PA is present in normal cornea and cultured corneal epithelial cells and that it is in a latent form (proactivator), whereas alkali-burned corneae are rich in active PA. Plasminogen activator has been shown to stimulate latent collagenase production in fibroblast cultures and organ-cultured alkali-burned corneal stroma. Plasmin can generate collagenase, which is recognised to have an important role in stromal destruction after alkali burns. The appearance of active collagenase in alkali-burned cornea correlates with the appearance of high levels of active PA in that tissue.

With this background we looked at the PA-plasmin system of human tears using routine extracapsular cataract surgery with intraocular lens implantation as a model for ocular injury. This had the attraction of providing an inflammatory model with a relatively standardised time course in which inflammatory events such as vasodilatation, increased vascular permeability and the outpouring of polymorphonuclear cells into tears were known to occur. ${ }^{13} \mathrm{We}$ were interested in the effects of glucocorticoids and of limbal versus corneal section as an operative procedure on the PA-plasmin system.

\section{METHODS AND MATERIALS}

\section{Chromogenic Assay of Plasminogen Activator}

Plasminogen activator was measured by a chromogenic assay. ${ }^{14}$ Tear samples are taken using a $10 \mu$ l glass capillary tube in contact with the inferior marginal tear-strip, at the junction of the lateral quarter and medial three quarters of the lower eyelid. About $10 \mu \mathrm{l}$ of tears were taken up to a pre-set mark and the tear sample was immediately transferred to a microcentrifuge tube (Ependorff), then frozen and stored at $-20^{\circ} \mathrm{C}$. Samples were assayed in microtitre plates by a plasminogen-coupled chromogenic substrate (S-2251; Val-Leu-Lys-pNA) method in the presence of cyanogen bromide-fragmented fibrinogen as stimulator. The absorbance of the generated $p$-nitroanilide was measured spectrophotometrically using a microtitre plate reader set at $405 \mathrm{~nm}$ (Multiscan MC-Flow Laboratories). By comparing the absorbance of the samples with a standard curve of human t-PA, the t-PA-like activity was derived.

\section{Zymography}

To determine the PA species, SDS-polyacrylamide gel electrophoresis (SDS-PAGE) was carried out followed by fibrin enzymography. ${ }^{15,16}$ Tear samples were electrophoresed with t-PA and u-PA standards for 5 hours at 30 milliamps per gel. Following electrophoresis the gel was soaked in $2.5 \% \mathrm{v} / \mathrm{v}$ Triton X-100 for 2 hours, then placed on a fibrin-agarose composite bonded to Gel-Bond and incubated at $22{ }^{\circ} \mathrm{C}$ for $16-24$ hours. Active PA was indicated by clear lysis of the opaque fibrin background and a permanent record was made by drying and staining the overlay with amido-black (Fig. 1). Molecular weight standards (Pharmacia Ltd.) run on the same gel were used to estimate the molecular weight of the active enyzmes and complexes.

\section{Characterisation of $P A$}

To confirm the identity of the PA found in tears, rabbit anti-human t-PA IgG was incorporated into the fibrinagarose overlays.

\section{Identification of PA-Plasmin Inhibitors}

To investigate the presence of PA-plasmin inhibitors, reverse fibrinolysis enzymography was performed $.^{17} \mathrm{Fol}-$ lowing SDS-PAGE the gel was overlaid with a fibrinagarose film incorporating $0.2 \mathrm{IU} \mathrm{cm} \mathrm{cm}^{3}$ urokinase and incubated at $22{ }^{\circ} \mathrm{C}$ for $16-24$ hours. The presence of inhibitor was seen in the overlay as areas of opaque fibrin against a lysed background. The undigested zones of fibrin were stained dark with amido-black (Fig. 2).

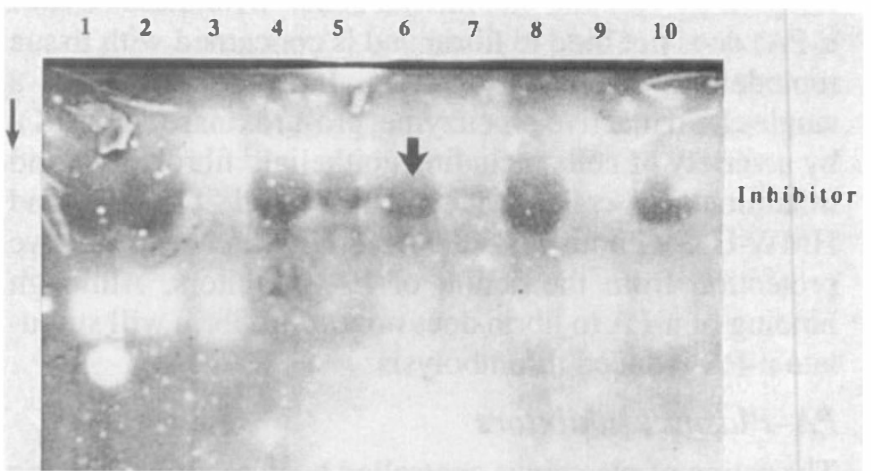

Fig. 2. Reverse zymography showing the presence of PA inhibitor (as yet unidentified). Long arrow shows direction of movement during electrophoresis. Horizontal line across figure is the starting line for the samples. The short arrow in lane 6 shows the presence of inhibitor. Lanes: 1,8 and 10, pre-operative; 2, 3 and 7, day 1 post-operative; 4, 5 and 6, day 2 post-operative. Lanes 1 , $2,4,5,6,8$ and 10 show the presence of inhibitor. 


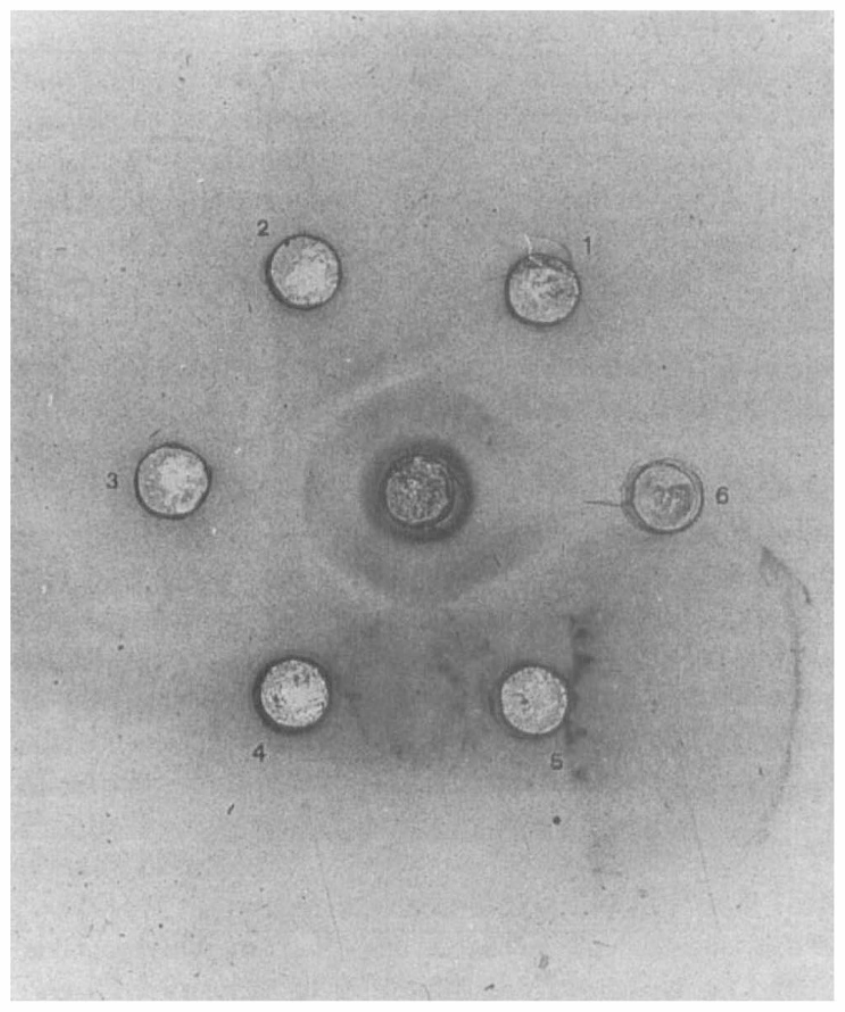

Fig. 3. Ouchterlony plates showing single and double immunoprecipitate lines of identity. Rabbit anti-human plasminogen is placed in the central well and tear samples in the peripheral ones. Samples: 1, pre-operative; 2, 3,4 and 5, post-operative; 6 , no sample was placed in this well. Note the absence of a line of identity opposite well 6.

\section{Detection of Plasminogen}

The presence of plasminogen antigen in tears was demonstrated by Ouchterlony immunodiffusion ${ }^{18}$ using rabbit anti-human plasminogen antisera. The presence of plasminogen and of plasminogen breakdown products or complexes was signified by single or double immunoprecipitin lines of identity (Fig. 3).

\section{Patients}

Tear samples were collected from 30 patients who underwent routine extracapsular cataract extraction with posterior chamber lens implantation. Samples were collected pre-operatively, and on the first and second post-operative days. In a few patients tears were collected after 2 and 6 weeks post-operatively.

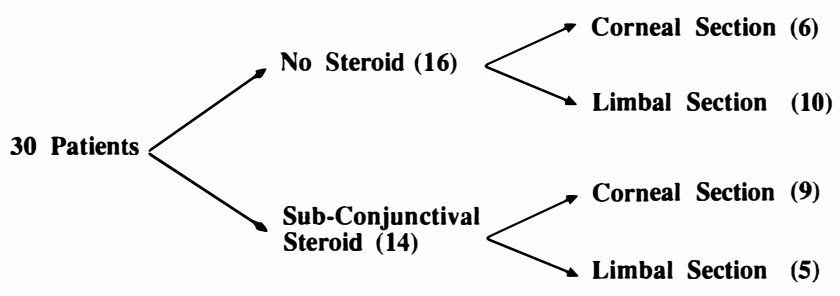

Fig. 4. The randomisation of patients into groups either receiving subconjunctival steroid at operation or not. A proportion of those not having subconjunctival steroid went on to receive topical betamethasone on day 1 and day 2 post-operatively.

Patients were stratified to receive either no subconjunctival steroid at the end of surgery or $4 \mathrm{mg}$ betamethasone. All patients received subconjunctival gentamicin $20 \mathrm{mg}$ at the end of surgery. In each group some patients received limbal sections with a formix-based conjunctival flap, and some corneal sections. Of the 16 who received subconjunctival steroid, 6 patients ( 3 with limbal and 3 with corneal sections) received no topical steroid in the first 2 post-operative days while the remainder received betamethasone four times daily from day 1 (Fig. 4).

\section{RESULTS}

Pre-operative samples (Table I) all contained PA activity. Zymography on pre- and post-operative tear samples demonstrated t-PA activity $\left(M_{\mathrm{r}} 68 \mathrm{k}\right)$ but not u-PA activity $\left(M_{\mathrm{r}} 57 \mathrm{k}\right.$ or $\left.36 \mathrm{k}\right)$ (Fig. 1). The presence of t-PA antigen was confirmed by zymography with t-PA antibodies in both pre- and post-operative tear samples. All fibrinolytic activity was completely inhibited by specific antibody to t-PA. In addition fibrinolytic activity to t-PA corresponding to a higher molecular weight was also observed in some samples, which may represent a t-PA complex.

Repeated $10 \mu \mathrm{l}$ sampling from a single conjunctival sac is associated with a fall in PA activity (Fig. 5) and, on an arbitrary basis, the first $10 \mu \mathrm{l}$ sample was used in this study.

Data were further analysed for an effect of limbal versus corneal section on tear PA levels and for an effect of the introduction of topical betamethasone post-operatively in those patients not receiving per-operative steroids. The majority of corneal section patients who received no peroperative steroid showed a rise in PA activity on the first post-operative day (Fig. 6) while those receiving peroperative steroid showed a fall (Fig. 7). This fall is signifi-

Table I. The median tear PA activities in pre- and post-operative patients who did (A) and did not (B) receive per-operative subconjunctival betamethasone

\begin{tabular}{lcc}
\hline & \multicolumn{2}{c}{ Median tear PA activity $\left(\mathrm{IU} / \mathrm{cm}^{3}\right)$} \\
\cline { 2 - 3 } & Pre-operative & Post-operative \\
\hline Group A: patients receiving per-operative steroid $(n=14)$ & 3.2 & 2.4 \\
Group B: patients receiving no per-operative steroid $(n=16)$ & (range $0.65-12.3)$ & (range $0.73-7.1)$ \\
& (range 0.56-20.1) & (range 0.76-21.1) \\
\hline
\end{tabular}

In group $\mathrm{A}$, the post-operative median tear PA activity fell on the first post-operative day. This fall is significant $(p=0.041)$. In group B, the postoperative median tear PA activity rose on the first post-operative day. The rise is significant $(p=0.0031)$ using the Wilcoxon matched pairs signed ranks test. There was no significant difference in the PA values between the two groups pre-operatively (Mann-Whitney $U$-test). The median level of PA activity in normal pre-operative tears was $2.21 \mathrm{IU} / \mathrm{cm}^{3}(n=29)$. 


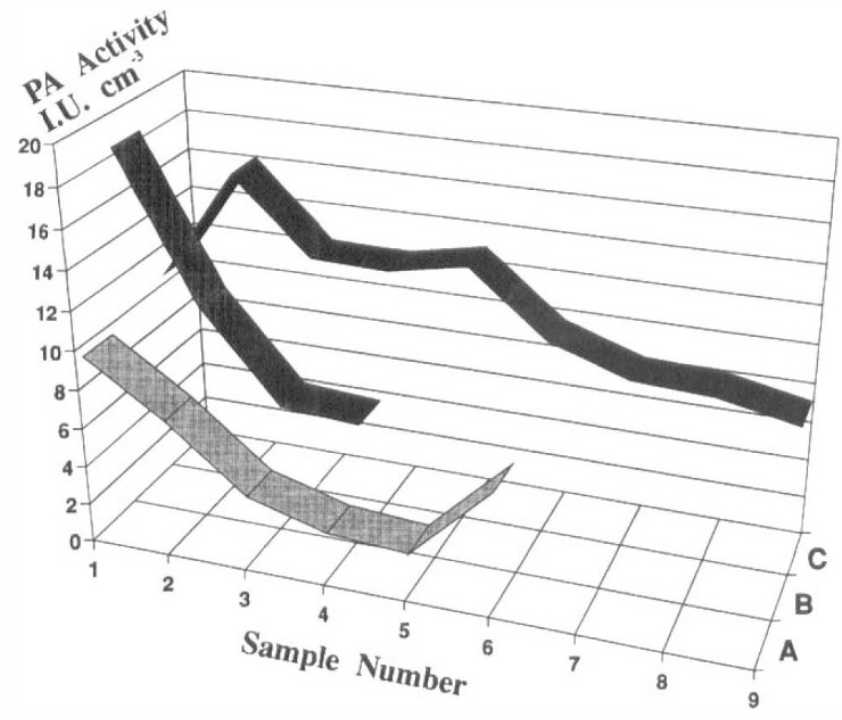

Fig. 5. PA activity in the tears of three patients $(A, B, C)$ with the samples taken sequentially from each patient. The trend is for the activity to fall in successive samples, which may be due to progressive dilution of the tears by PA-poor lacrimal fluid.

cant $(p=0.041)$. Limbal section patients also showed a difference in post-operative PA activity between no steroid (Fig. 8) and steroid-treated groups (Fig. 9), but this is not statistically significant, the numbers in each group being small and the scatter of values wide.

Immunodiffusion studies confirm the presence of plasminogen in both pre- and post-operative tear samples, indicating that the substrate for plasmin formation is present in both situations (Fig. 3). Reverse zymography studies on pre-operative tear samples show the presence of an inhibitor to u-PA. This was, however, usually absent in post-operative (first day) tear samples, which may reflect the increased levels of activity in such samples.

\section{PA Activity}

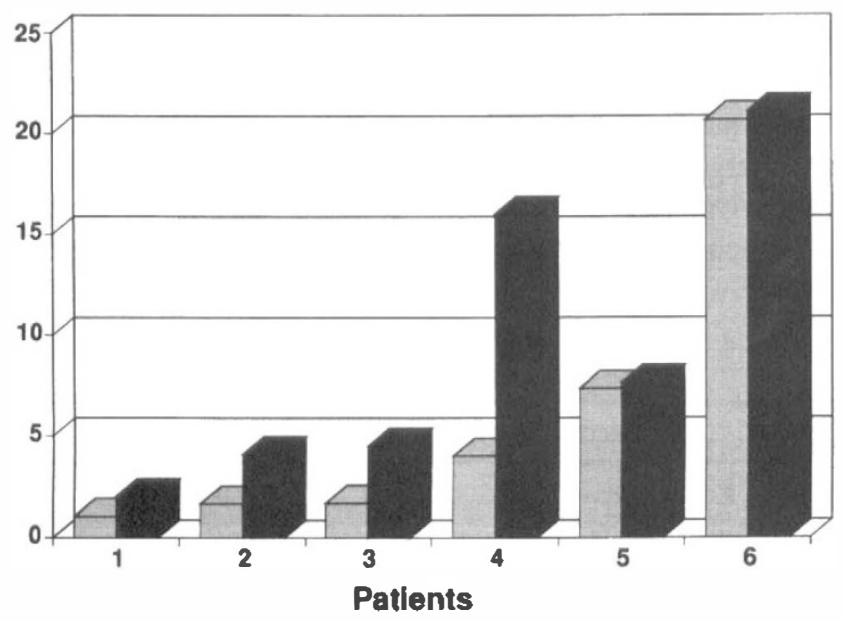

Fig. 6. The difference between pre-operative (light columns) and post-operative (dark columns) tear PA activity $\left(I U / \mathrm{cm}^{3}\right)$ in the 6 corneal section patients who did not receive per-operative subconjunctival steroid.The mean PA level rose on the first postoperative day.

\section{PA Activity}

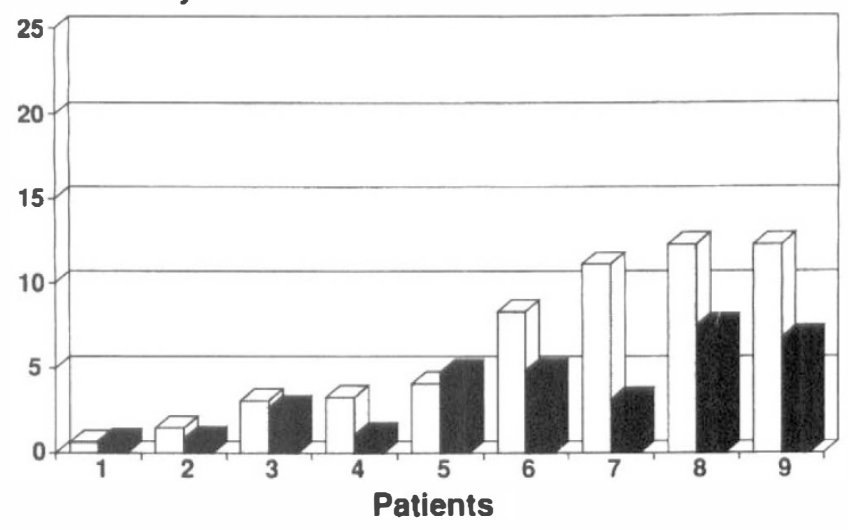

Fig. 7. The difference between pre-operative (light columns) and post-operative (dark columns) tear PA activity $\left(I U / \mathrm{cm}^{3}\right)$ in the 9 corneal section patients who received per-operative subconjunctival steroid. The mean PA level fell on the first postoperative day.

\section{PA Activity}

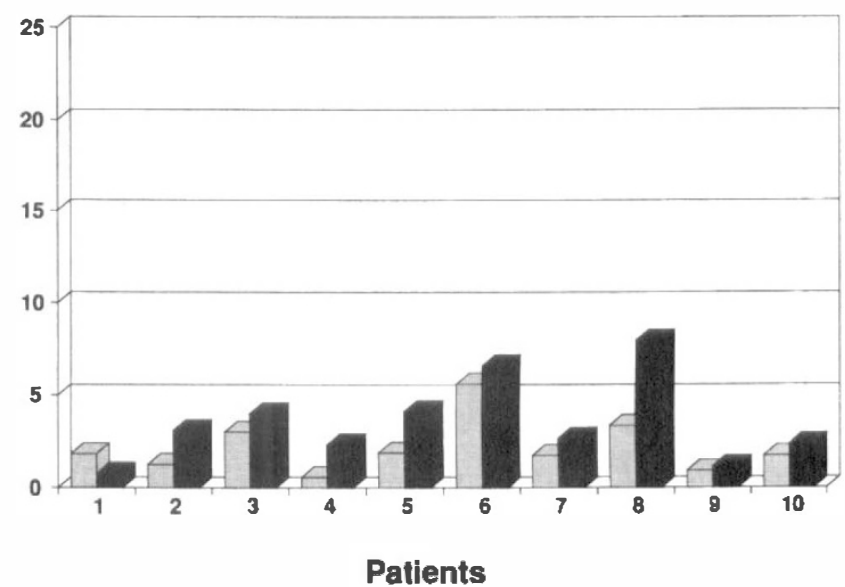

Fig. 8. The difference between pre-operative (light columns) and post-operative (dark columns) tear PA activity $\left(I U / \mathrm{cm}^{3}\right)$ in 10 limbal section patients who did not receive subconjunctival steroid.

\section{PA Activity}

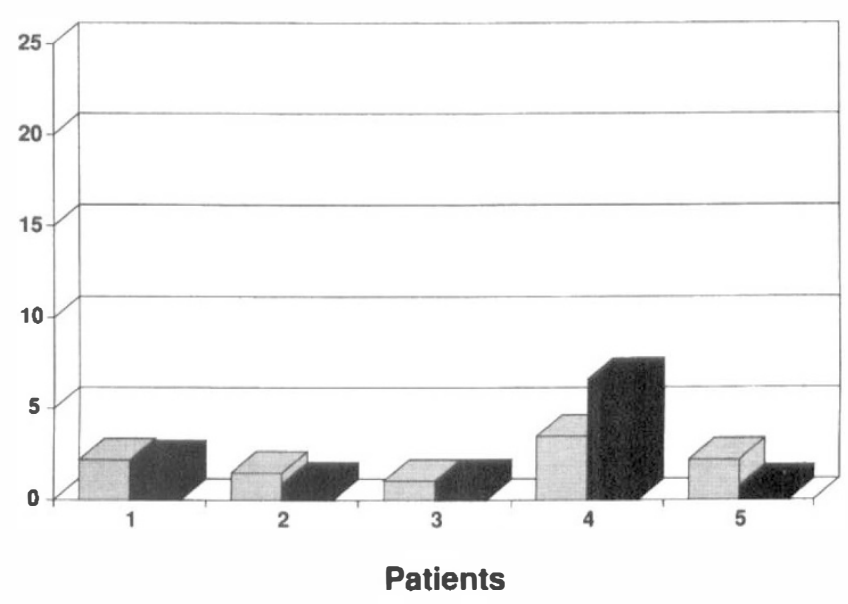

Fig. 9. The difference between pre-operative (light columns) and post-operative (dark columns) tear PA activity $\left(I U / \mathrm{cm}^{3}\right)$ in 5 limbal section patients who received per-operative subconjunctival steroid. 


\section{DISCUSSION}

The collection and storage system used in this study was arrived at by trial and error. The tear volume available from individual patients varied, as did the reflex tearing that results from the collection procedure, though there are plentiful tears in the conjunctival sac of post-operative patients compared with pre-operative patients. Repeated $10 \mu \mathrm{l}$ sampling from a single conjunctival sac is associated with a fall in PA activity which is assumed to be due to a progressive dilution of the tears by PA-poor lacrimal fluid (Fig. 5).

Earlier studies in which $10 \mu \mathrm{l}$ samples were stored dry in microwells at $-20{ }^{\circ} \mathrm{C}$ gave widely variable results, and this procedure was therefore not continued. There was considerable variation in PA values between patients and the factors responsible have not yet been fully explored. It is likely that they include patient variation, the effects of surface trauma during collection, reflex tearing and of loss of activity on transport, and storage or thawing of samples. Freeze-dried material kept for up to some months lost activity completely.

The PA assay system used here measures total PA-like activity (t-PA and u-PA) but does not take into account the possible presence of inhibitors or stimulators of the PAplasmin system. Evidence for the presence of inhibitor was found in tears of unoperated eyes by performing reverse zymography. The disappearance of inhibitor from a number of post-operative samples is of interest in suggesting one mechanism by which PA-plasmin activity might be increased following the trauma of surgery. It is, however, perhaps surprising, since the increase in vascular permeability following surgery would be expected to release blood-borne natural inhibitors into the tear sac. Removal of inhibitor could imply a complexing of available inhibitor to substrate, such as plasmin, or dilution of tears by an inhibitor-poor lacrimal fluid.

On the basis of zymography with anti-t-PA antibody, the PA activity of pre- and post-operative tear samples was attributed to the presence of t-PA. No u-PA activity was demonstrated in any sample. this is consistent with Rijken et al. ${ }^{19}$ and Thorig et al. ${ }^{20}$ who found only t-PA in unstimulated and stimulated human tears. However, Wang et al. ${ }^{12}$ demonstrated PA in normal and corneal ulcer tears to be immunoreactive to antibodies to u-PA $\left(M_{\mathrm{r}} 33 \mathrm{k}\right)$ and Hong and Beebe ${ }^{21}$ found only u-PA in tears from normal and injured rabbit eyes. Hayashi and Sueishi, ${ }^{22}$ using fibrinolytic zymography, identified both t-PA and u-PA activity in normal human tears, giving values for $t$-PA of $5.2 \pm 1.3 \mathrm{IU} / \mathrm{cm}^{3}$ and for u-PA of $2.8 \pm 0.5 \mathrm{IU} / \mathrm{cm}^{3}$ $(n=6)$. These discrepancies are not resolved. In our zymographic studies, fibrinolytic zones were present in some samples at positions corresponding to a higher molecular weight than t-PA; this is assumed to be due to the presence of PA-complexes, as yet uncharacterised.

The immunodiffusion studies detected material which reacted with antibody raised against plasminogen. This antibody cross-reacts with plasmin, but since plasmin has not been detected in normal tears it may be assumed that a positive precipitation line signifies the presence of plasminogen. The precipitation lines in post-operative samples could be either plasminogen, plasmin or both. The specific form, or forms, in which PA is released at the surface of the eye in various conditions, including surgical trauma, is important in determining the site of plasmin formation. Tissue PA would be expected to locate at the site of a wound or epithelial defect where fibrin is known to accumulate. This would have an important regulatory function in wound healing, facilitating cell movement and removal of extracellular matrix proteins.

The response to surgical trauma in the absence of steroid exposure was a significant rise in tear PA activity. Exposure to per-operative betamethasone resulted in a significant fall in tear PA activity, an effect seen with the combined limbal section and corneal section patients, and also when the corneal section patients were considered alone $(p=0.041)$. Limbal section patients also appeared to have reduced PA activity with exposure to per-operative steroid, though the effect did not reach significance in this study, the numbers being small. Median pre-operative PA levels in the steroid and no-steroid groups differed, though the difference was not statistically significant.

The difference in tear PA activity between steroidtreated and untreated eyes is of interest and has some support in other systems. Crutchley et $a .^{23}$ demonstrated a decrease in extractable PA activity from cultured fibroblasts exposed to glucocorticoids, which was attributed to the production of PA inhibitor. If such an effect of steroids on the eye is confirmed, it would appear to act in an opposite manner to the well-known effect of glucocorticoids in diminishing wound strength, since it would result in a conservation of extracellular matrix proteins and a diminished activation of collagenase. However, an effect of steroid could simply relate to the intensity of granulocyte invasion of tears following surgery or to an action on the inhibitory system. The finding of increased PA activity in tears after cataract extraction may have relevance in wound healing as excessive tear plasmin activity may cause $\mathrm{FN}$ to be digested resulting in possible retarded healing. ${ }^{7}$ Reduction in post-operative PA activity with the use of subconjunctival betamethasone may be beneficial to allow early wound healing.

Key words: Cataract, Human, Plasminogen activator, Surgery, Tears, Tissue plasminogen activator, Urokinase.

\section{REFERENCES}

1. Bachmann F: Fibrinolysis. In: Verstraete M, Vermylen J, Lijnen HR, Amout J, eds. Thrombosis and Haemostasis. Leuven: International Society on Thrombosis and Haemostasis and Leuven University Press, 1987: 227-65.

2. Lantz E and Anderson A: Release of fibrolyte activators from the cornea and conjunctiva. Graefes Arch Clin Exp Ophthalmol 1982, 19: 263-7.

3. Berman M, Leary R, Gage J: Evidence for a role of the plasminogen activator-plasmin system in corneal ulceration. Invest Ophthalmol Vis Sci 1980, 19: 1204-21.

4. Tripathi BJ, Geanon JD, Tripathi RC: Distribution of tissue plasminogen activator in human and monkey eyes. Opthalmology 1987, 94: 1434-8. 
5. Geanon JD, Tripathi BJ, Tripathi RC, Barlow GH: Tissue plasminogen activator in avascular tissue of the eye: a qualitative study of its activity in cornea, lens, and aqueous and vitreous humour of dog, calf and monkey. Exp Eye Res 1987, 44: 55-63.

6. Park JK, Tripathi RC, Tripathi BJ, Barlow GH: Tissue plasminogen activator in the trabecular endothelium. Invest Ophthalmol Vis Sci 1987, 28: 1341-5.

7. Berman M, Manseau E, Law M, Aiken D: Ulceration is correlated with degradation of fibrin and fibronectin at the corneal surface. Invest Ophthalmol Vis Sci 1983, 24: 1358-66.

8. Pierschbacher MD and Ruoslahti E: Cell attachment activity of fibronectin can be duplicated by small synthetic fragments of the molecule. Nature 1984, 309: 30-3.

9. Avery R and Glaser BM: Inhibition of retinal pigment epithelial cell attachment by a synthetic peptide derived from the cell-binding domain of fibronectin. Arch Opthalmol 1986, 104: 1220-2.

10. Salonen EM, Tervo T, Torma E, Tarkkanen A, Vaheri A: Plasmin in tear fluid of patients with corneal ulcers: basis for new therapy. Acta Opthalmol (Copenh) 1987, 65: 3-12.

11. Hayashi K, Berman M, Kenyon K, Pease S: Pathogenesis of epithelial defects and stromal ulceration: localisation of tissue plasminogen activator and urokinase-like activator in scraped and alkali burned corneal wound healing models. Invest Ophthalmol Vis Sci 1987, 28: no. 3 ARVO abstract 1987: 2.

12. Wang H-M, Berman M, Law M: Latent and active plasminogen activator in corneal ulceration. Invest Ophthalmol Vis Sci 1985, 26: 511-24.

13. Bron AJ: Quantification of external ocular inflammation. In: Holly FJ, ed. The Preocular Tear Film in Health, Disease and Contact Lens Wear. Dry Eye Institute, 1986: 776-87.

14. Verheijen JH, Mullart E, Chang GTG, Kluft C, Wijngaards $\mathrm{G}$ : A simple, sensitive spectrophotometric assay for extrin- sic (tissue-type) plasminogen-activator applicable to measurements in plasma. Thromb Haemost 1982, 48: 266-9.

15. Granelli-Piperno A and Reich E: A study of proteases and protease-inhibitor complexes in biological fluids. $J$ Exp MEd 1978; 148: 223-34.

16. Marshall JM, Rees MCP, Cederholm-Williams SA: Identification of t-PA as the major active plasminogen activator in human milk. Thromb Haemost 1986, 55: 279-81.

17. Loskutoff DJ, van Mourik JA, Lawrence D: Detection of an unusually stable fibrinolytic inhibitor produced by bovine endothelial cells. Proc Natl Acad Sci USA 1983, 80: 2956-60.

18. Ouchterlony $\mathrm{O}$ and Nilsson L: Immunodiffusion and immunoelectrophoresis. In: Weir D, ed. Immunohistochemistry: Handbook of Experimental Immunology, vol 1, Oxford: Blackwell Scientific, 1973, 19-39.

19. Rijken DC, Wijngaards G, Wellbwegen J: Immunological characterisation of plasminogen activator activities in human tissues and body fluids. J Lab Clin Med 1981, 97: 477-86.

20. Thorig L, Wijngaards G, van Haeringen NJ: Immunological characterisation and possible origin of plasminogen activator in human tear fluid. Ophthalmic Res 1983, 15: 268-76.

21. Hong BS and Beebe WE: Effects of endotoxin injection and wounding of corneal epithelium on the plasminogen activator activity in rabbit tears. In: Holly FJ, ed. The Preocular Tear Film in Health, Disease and Contact Lens Wear. Dry Eye Institute, 1986: 865-75.

22. Hayashi K and Sueishi K: Fibrinolytic activity and species of plasminogen activator in human tears. Exp Eye Res 1988, 46: 131-7.

23. Crutchley OJ, Conan LB, Maynard JR: Human fibroblasts produce inhibitor directed against plasminogen activator when treated with glucocorticoids. Ann NY Acad Sci 1981, 370: 609-16. 